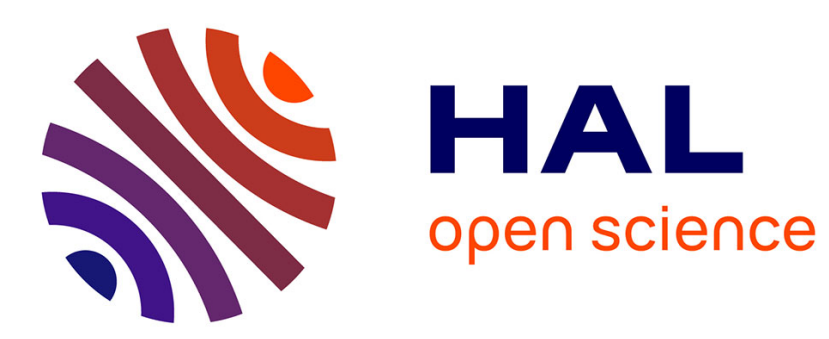

\title{
The birth of classical genetics as the junction of two disciplines: conceptual change as representational change \\ Marion Vorms
}

\section{To cite this version:}

Marion Vorms. The birth of classical genetics as the junction of two disciplines: conceptual change as representational change. Studies in History and Philosophy of Science Part A, 2014, 48, pp.105-116. 10.1016/j.shpsa.2014.05.007 . halshs-01122308

\section{HAL Id: halshs-01122308 \\ https://shs.hal.science/halshs-01122308}

Submitted on 7 Jun 2021

HAL is a multi-disciplinary open access archive for the deposit and dissemination of scientific research documents, whether they are published or not. The documents may come from teaching and research institutions in France or abroad, or from public or private research centers.
L'archive ouverte pluridisciplinaire HAL, est destinée au dépôt et à la diffusion de documents scientifiques de niveau recherche, publiés ou non, émanant des établissements d'enseignement et de recherche français ou étrangers, des laboratoires publics ou privés. 
THE BIRTH OF CLASSICAL GENETICS AS THE JUNCTION OF TWO DISCIPLINES: CONCEPTUAL ChANGE AS REPRESENTATIONAL CHANGE

\author{
Marion VORMS \\ marion.vorms@ens. $\mathbf{f r}$ \\ University Paris 1, IHPST (CNRS) \\ 13 rue du Four
}

75006 Paris, France

\begin{abstract}
The birth of classical genetics in the 1910's was the result of the junction of two modes of analysis, corresponding to two disciplines: Mendelism and cytology. The goal of this paper is to shed some light on the change undergone by the science of heredity at the time, and to emphasise the subtlety of the conceptual articulation of Mendelian and cytological hypotheses within classical genetics. As a way to contribute to understanding how the junction of the two disciplines at play gave birth to a new way of studying heredity, my focus is on the forms of representation used in genetics research at the time. More particularly, I study the design and development, by Thomas H. Morgan's group, of the technique of linkage mapping, which embodies the integration of the Mendelian and cytological forms of representation. I show that the design of this technique resulted in a genuine conceptual change, which should be described as a representational change, rather than merely as the introduction of new hypotheses into genetics.
\end{abstract}

\title{
Keywords
}

Conceptual change

Disciplines

Genetics

Maps

Thomas H. Morgan

Representation 


\section{INTRODUCTION}

The early history of classical genetics provides us with a fascinating case of interdisciplinary research. The laying and consolidation of its essential components, in the 1910's and 1920 's, resulted to a large extent from the integration of two modes of analysis, corresponding to two different disciplines: the Mendelian study of heredity (Mendelism), and cytology. Mendelism is concerned with the probabilistic laws governing the transmission of hypothetical hereditary units - the genes -, of whose material nature it says nothing. Cytology is the study of cells and cellular processes. Classical genetics, as it is used and taught today, comprises both Mendelian hypotheses about the genes' transmission patterns, and cytological hypotheses about the physical processes underlying these patterns.

The relations of Mendelian and cytological hypotheses within classical genetics have not drawn much interest from philosophers of science. The integration of cytological hypotheses into genetics in the 1910's is generally thought of as a first step towards the materialisation of the gene, which was achieved by molecular biology four decades later. Philosophers seem to consider that this step, although historically fascinating, is not conceptually problematic, and that the interesting issue is whether classical genetics (as including both Mendelian and cytological hypotheses) is reducible to molecular biology. ${ }^{1}$

The goal of this paper is to shed some light on the change undergone by the science of heredity in the 1910's, and to emphasise the subtlety of the conceptual articulation of Mendelian and cytological hypotheses within classical genetics. As a way to contribute to understanding how the junction of the two disciplines at play gave birth to a new way of studying heredity, my focus will be on the forms of representation used in genetics research at the time. ${ }^{2}$

In section 2, I present the disciplinary framework in the early 1900's, and I characterise the typical forms of representation associated with Mendelism and cytology respectively. In section 3, I explain how empirical novelties in the early 1900's

\footnotetext{
1 For the reducibility/irreducibility debate, see Schaffner, 1969; Hull, 1972; Wimsatt, 1976; Darden \& Maull, 1977; Kitcher, 1984; Burian, 1985; Rosenberg, 1985; Waters, 1990.

2 My approach, though relying on a historical case study, is a philosophical one; I do not claim to contribute to our historical knowledge of the period.
} 
resulted in the formulation of new hypotheses in the two domains, and how these hypotheses together gave birth to an interdisciplinary research program. In section 4 , I analyse the technique of linkage mapping, which is at the core of this research program, and embodies the integration of the Mendelian and cytological forms of representation.

\section{THE DISCIPLINARY FRAMEWORK: MENDELISM, CYTOLOGY, AND THEIR ASSOCIATED FORMS OF REPRESENTATION}

After saying a few words about the methodological choice of focusing on forms of representation, I will characterise the typical forms of representation of Mendelism and cytology. Finally, I will briefly sketch how scientists conceived of the relations between these two domains in the early 1900's.

\subsection{Disciplines and forms of representation.}

As Kuhn (1970a) famously emphasised, scientific disciplines can be characterised by reference to a cluster of heterogeneous things, ranging from the use of concrete instruments and experimental practices, to abstract entities such as laws or models. ${ }^{3}$ Here, I will focus on the conceptual elements among this cluster. But, rather than laws and concepts taken as abstract, linguistic entities, I will study the concrete, external representations that are produced, used, and reasoned with by the practitioners of a discipline, and with which students have to get familiar when specialising in it.

Textbooks, as well as research papers and presentations, contain representations of many different forms: equations, graphs, diagrams, schematic drawings, pictures, etc. Giving a

\footnotetext{
3 It is beyond the scope of this paper to comment on the notoriously polysemic notion of paradigm. As Kuhn (1969, 1970b) himself acknowledges, "paradigms" can refer to things as different as the whole cluster of heterogeneous things described above (that he would call a "disciplinary matrix") on the one hand, and particular forms of equations or typical problem-solutions ("exemplars"), on the other. Without assessing the coherence of Kuhn's views, I wish to emphasise one aspect of his approach, which is also characteristic of mine: paradigms serve an epistemological characterisation of scientific disciplines, rather than a sociological one. Paying attention to disciplines and scientific communities rather than (exclusively) to theories does not constitute a shift from philosophy to sociology, but rather a novel approach to the epistemological issues that philosophy of science traditionally tackles.
} 
precise characterisation of these representational forms is a worthwhile project, but quite beyond the scope of this paper. Suffice it to say that the form of a representational device is determined by the structural features, by which it refers to its target and encodes information about it - or, borrowing Nelson Goodman's (1976) tools, by the syntax and the semantics of the symbol system, in which it functions as a representation. One can then categorise representations of different forms into broad types, such as linguistic, diagrammatic, schematic, and pictorial." Since Goodman's seminal work, it is commonplace to admit that the same material device (or "set of marks") can function as a representation of different things: a "black wiggly line" can be a diagrammatic representation of heartbeats ("momentary electrocardiogram") as well as a (pictorial, or schematic) "drawing of Mt Fujiyama" (Goodman, 1976, pp. 229230). Conversely, the same object can be represented in different ways: different types of representations might not convey the same kind of information about it.

Extending this to scientific representations, one assumption that guides this paper is that considering the typical form(s) of representation associated with a given discipline is a fruitful way to capture aspects of its mode of analysis. By "mode of analysis", I refer to the way a discipline conceives of its subject matter - how phenomena are categorised, and reasoned about. Philosophical analyses of the content of scientific theories often focus on laws and concepts, analysing what the referents of these concepts (e.g. "genes") are, and what the laws say about them. Studying forms of representations is a way to shed light on some aspects that are obscured or neglected by these more traditional approaches, such as how a discipline construes its objects (e.g. whether genes are represented as abstract, or concrete), what is implicitly assumed or left undecided about them, and what kind of reasoning is led on them (e.g. statistical, mechanistic). I hope to show the fruitfulness of this approach by applying it to classical genetics, whose birth was the result of the integration of the modes of analysis of Mendelism and cytology. ${ }^{5}$

\footnotetext{
4 I elaborate this typology in (Vorms, 2009, chap. 7). In the present paper, the distinction that matters is between diagrams and schematic drawings; I present it briefly in subsections 2.2 .2 and 2.3.

5 The project of studying conceptual change by focusing on concrete, nonlinguistic, representations was remarkably implemented by Griesemer and Wim-
} 


\subsection{Mendelism.}

What I call "Mendelism" is to be clearly distinguished from what is usually called "classical genetics" - and sometimes "Mendelian genetics". Mendelism studies the transmission patterns of the genes, without any assumption as to what their physical basis is. It corresponds to the study of heredity before the adjunction of the cytological components of classical genetics. It also corresponds to a particular mode of analysis within classical genetics. The birth of Mendelism so defined dates back to the rediscovery of Mendel's laws in 1900.6 William Bateson called this field "genetics" in 1905.7

\subsubsection{Experimental method: breeding experiments.}

The experimental method of Mendelism consists of breeding (hybridisation) experiments, where the transmission of hereditary factors is traced back from statistical data concerning the distribution of the observable characters among individuals in successive generations. Breeding experiments rely on the choice of differential characters (e.g. green versus yellow colour in sweet peas).

The fundamental hypothesis underlying this experimental practice is that the observable characters of individuals are caused ${ }^{8}$ by hereditary factors, called "genes". 9 In multicellular organisms with sexual reproduction, each individual is supposed to possess a pool of genes resulting from an equal participation of his/her parents. Hence, each individual has an even number of genes (for each non-sex-linked character, he/she has two genes,

satt (1989), in their study of the evolution of Weismann's diagrams. Here, rather than the evolution of one discipline, I study how two disciplines integrated into one novel way of conceiving of heredity. It is worth insisting that, like Griesemer and Wimsatt's, and unlike Kohler's (1994) socioconstructivist study of the experimental and representational practices of the geneticists in the early 20 th century, I aim at studying the conceptual content of classical genetics (although, to be sure, forms of representations are closely related to experimental practices).

6 Note that Mendelian theory so defined does not correspond to Mendel's theory, but rather to the theory developed by the geneticists in the 1900 's.

7 See Dunn, 1965, p. 69.

8 More precisely, a gene difference causes a phenotypic difference (see Waters $1994)$.

9 Wilhelm Johannsen introduced the term "gene" in 1909. But, until 1917, Morgan's group would rather speak of "Mendelian factors". 
also called "alleles"), one half of them coming from the male parent and the other half from the female parent. At the core of the Mendelian method is a certain conception of genes, which reflects in the very symbolism Mendel introduced in his memoir. ${ }^{10}$

\subsubsection{Symbolism: genes as operational units.}

The Mendelian symbolism consists of representing the genes as discrete, stable entities, by means of letters (or icons), on which combinatorial mathematics is applied. For instance, the equation

\section{$9 A B+3 A b+3 a B+a b$}

expresses the expected distribution of genes among the germ cells for a cross involving two genes - two pairs of differential characters. It can be considered as a symbolic expression of Mendel's second law, which I present below.

The Mendelian geneticists in the early 1900's developed this symbolism into other forms of representation. For instance, the double entry arrays called "Punnett squares" are spatial (two-dimensional) extensions of this symbolism. They enable one to easily calculate the distribution of genotypes among individuals in successive generations. They may also facilitate one's understanding of the Mendelian theory itself, by expressing Mendel's laws (see fig. 1 and 2), or other probabilistic rules about the transmission patterns of some particular genes in a given species.

\footnotetext{
10 It is not clear what exactly Mendel (1866) intended to represent by the letters (germs cells or "genes"?). For what we call "homozygous" individuals, he would use only one letter, rather than two ( $A$, rather than $A A$, as did the geneticists in the early 1900's). Anyhow, he undeniably introduced a certain way of representing the genetic factors, namely as discrete entities, and of reasoning about them, by using combinatorial mathematics. On Mendel's "Mendelianism", see (Olby 1985).
} 


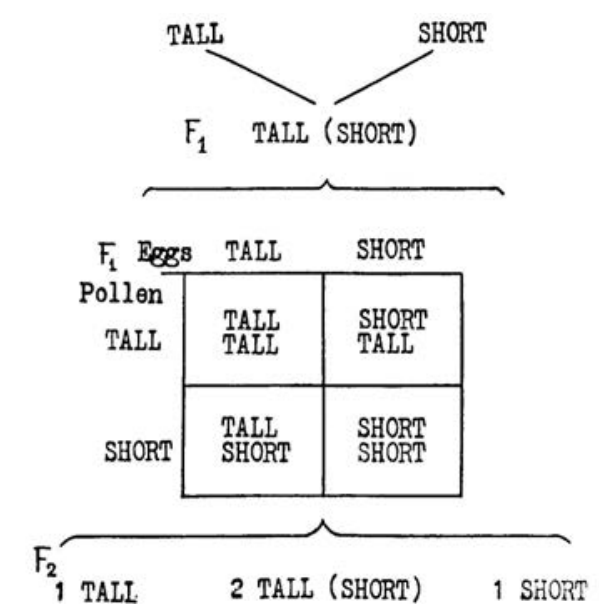

Fig. 1. Diagrammatic expression of Mendel's first law (Morgan, 1928 , p. 2 ).

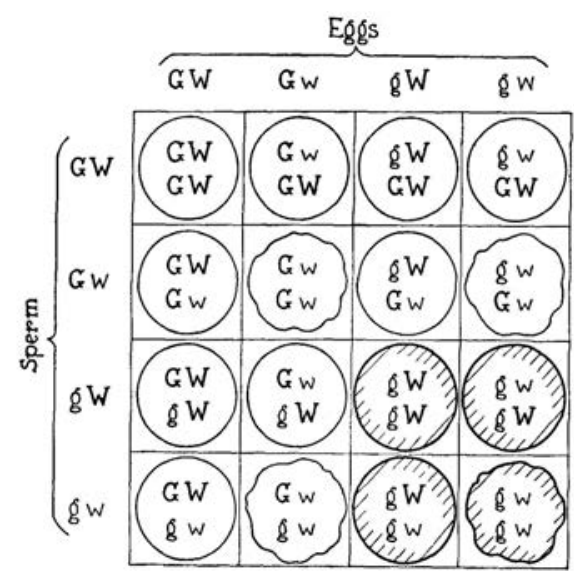

Fig. 2. Punnett square showing the expected distribution of genes among the germ cells for a cross involving two genes. It can also be considered as a diagrammatic expression of Mendel's second law (Morgan, 1928, p. 9).

Although they display information spatially, I consider Punnett squares as extensions of the Mendelian symbolism, because they do not introduce a new way of reasoning about genes. In fact, Punnett squares contain exactly the same information as their corresponding equations. The spatial display of the symbols standing for the genes might help computation ${ }^{11}$, but it does not tell us anything new about some spatial properties of the genes (anything that the equations would be unable to represent). As such, Punnett squares belong to the class of what I call diagrammatic representations. Diagrams, as opposed to schematic representations (see below) are a broad class of representations including graphs, arrays, flow charts, etc., which represent

\footnotetext{
11 In (Vorms, 2011, 2012), I elaborate the notion of format of representation, in order to account for the cognitive (inferential) differences caused by a difference in representation, which might not imply a difference of informational content. To borrow Simon and Larkin's (1987) terms, two representations in different formats might be "informationally equivalent" though "computationally different" (this is the case of Punnett squares and their corresponding equations). Although changes in formats might have important theoretical differences, as I show in the aforementioned papers, I am interested, in the present paper, in more radical differences. To be clear, let me stress that there are two ways of understanding the formula "An image is worth thousand words": either because an image spares one some cognitive effort and time to get some information, or because it enables one to convey content that thousand words cannot convey (see also Vorms, 2009, chap. 7).
} 
non-spatial relations (e.g. causal, hierarchical, or temporal relations) by means of spatial relations. ${ }^{12}$

Within such a representational framework, genes are mere hypothetical, unobservable entities. Using Mendelian symbolism does not imply any assumption about the physicochemical nature of genes, nor about their mode of action (the way they "cause" ${ }^{13}$ the characters). ${ }^{14}$ All what Mendelism says about genes is that they are transmitted from generation to generation following probabilistic laws, called "Mendel's laws".

\subsubsection{Mendel's laws.}

Mendel's first law (of "segregation") states that, in the formation of germ cells (sperms or pollen and eggs), the two alleles of each gene "segregate" so that each germ cell contains only one copy (one allele) of each gene responsible for a character. Any germ cell has an equal chance of containing one or the other allele of each gene.

Mendel's second law $^{15}$ (of "independent assortment") states that different pairs of genes assort independently from each other during the formation of germ cells. That means that the segregation of one pair of genes has no influence on the segregation of another pair. As appears in figures 1 and 2 showing the expected ratios for crosses involving one pair of genes (fig. 1) and two pairs of genes (fig. 2), these two laws can be expressed by means of the Mendelian symbolism.

\subsection{Cytology.}

Cytology is the study of cells and cellular processes. Cytological inquiry relies on imaging techniques (in particular the use of microscopes). Contrary to Mendelian geneticists, cytologists represent the objects they study (cells and their com-

\footnotetext{
12 See (Vorms, 2009, chap. 7) for a precise characterisation of diagrammatic and schematic representations (and other representational types).

13 See footnote 8 .

14 In fact, this agnosticism about the physicochemical nature of genes, and about their mode of action, is also characteristic of classical genetics (as including cytological hypotheses). Only molecular genetics addresses such issues, which are epigenetic in nature, and not genetic.

15 As Lindley Darden (1991, p. 139) notes, this law was not explicitly stated and distinguished from Mendel's first law until exceptions were found (see section 3 ).
} 
ponents, in particular chromosomes) as concrete, spatial entities. Ranging from microscope images to very schematic drawings, the representational devices they use enable them to gain, and express knowledge about the morphological properties of these entities, and about their spatiotemporal behaviour (e.g. the behaviour of chromosomes during mitosis and meiosis).

As such, cytological representations belong to the type of representations I propose to call "schematic". Schematic representations, unlike diagrammatic ones, represent spatial relations by means of spatial relations. The schematic drawing of a cell, or of a chromosome, might well be very different from the raw images obtained by the microscope. ${ }^{16}$ Theorising in cytology (partially) consists of interpreting, and abstracting away from, such raw images, by neglecting irrelevant information (for the sake of the hypotheses the drawing serves to express), and by highlighting some (often invisible) aspects of the represented object, such as the (theoretical) boundaries between its components. ${ }^{17}$ Hence, the schematic drawing of a cell or of a chromosome might well distort the distances. But it has to preserve the topological (if not the metric) properties of its target. Even when highly abstract, cytological representations remain schematic in the sense that spatial relationships do stand for spatial relationships. They could be mapped onto a microscope image of the same object.

\subsection{Relations between the two domains in the early 1900's.}

By the end of the $19^{\text {th }}$ century, cytologists had a fairly good knowledge of the behaviour of chromosomes ${ }^{18}$ during mitosis, namely the normal (i.e. non sexual) process of cell division. But the process of sexual cell division (meiosis) was still poorly understood in the early 1900's.

Yet, geneticists conceived of Mendelian segregation in terms of the formation of germ cells, and cellular processes were assumed to be the physical bases of genetic processes. Be-

\footnotetext{
16 The notion of "raw image" calls for clarification. Images obtained by microscope (or other imaging techniques) themselves result from an important work of data processing and interpretation, which might rely on theoretical hypotheses. But this is beyond the scope of my paper.

17 See (Lynch, 1988; Maienschein, 1991).

18 Chromosomes were identified in the $1880^{\prime} \mathrm{s}$, and described as having the shape of small sticks.
} 
yond that, though, hypotheses about the cytological bases of heredity were far from clearly understood. Nor was there any established hypothesis about what part of the cell is concerned with heredity. In the next section, I will present the key elements that led to the integration of cytological hypotheses into genetics, and to the birth of classical genetics.

\section{CLASSICAL GENETICS IN THE 1910'S: FROM CYTOLOGY TO MENDELISM, AND BACK}

The birth of classical genetics (defined as involving both Mendelian and cytological hypotheses) dates back to 1911, when Thomas H. Morgan adopted the chromosome theory of heredity, which states that the chromosomes are the physical basis of the genetic material. Morgan's conversion to this theory contributed to launch an interdisciplinary research program, whose most famous actors were the so-called "Drosophila group" (composed of Morgan and his students Alfred Sturtevant, Calvin Bridges, and Hermann Muller), and the cytologist Edmund Wilson at Columbia University •

The elaboration of the main components of classical genetics, as it is still taught today, was achieved in the 1910's and $1920^{\prime} \mathrm{s}$. In less than two decades, this interdisciplinary work yielded detailed knowledge of the transmission patterns of the genes in some model species (in particular Drosophila Melanogaster), together with the confirmation of the chromosome theory of heredity. Such confirmation was given by the establishment of correlations between the observed, spatiotemporal behaviour of chromosomes during the formation of germ cells and the statistical regularities in the transmission of genes.

After giving some precisions about the chromosome theory of heredity (3.1), I will present the empirical novelties (both in the Mendelian and in the cytological domains) that prompted Morgan's adoption of this theory (3.2). Morgan's conversion is historically indissociable from his formulation of the genetic theory of crossing-over, which I present in subsection 3.3. In the last subsection (3.4), I propose a first analysis of the conceptual change resulting from the joint adoption of the chromosome theory and the theory of crossing-over.

\subsection{The chromosome theory of heredity.}


The hypothesis that chromosomes are the physical basis of heredity, which finally prevailed, and is one of the essential components of classical genetics, was already put forward in the early 1900's by some geneticists and cytologists. Their intuition was based on an analogy between the behaviour of chromosomes and the law of segregation: pairs of homologous chromosomes appeared to join, and then disjoin, during successive phases of meiosis (Sutton, 1903; Boveri, 1904).

However, the advocates of the chromosome theory of heredity had still serious problems to face in the early 1900's. ${ }^{19}$ Morgan himself, who was to become a fervent advocate of the chromosome theory of heredity in 1911, still rejected it in 1910 (see Morgan, 1910a). ${ }^{20}$ Even after Morgan's "conversion", the chromosome theory was far from uncontroversial among the professional geneticists, until the early 1920's.

Moreover, because of the poor observational information one could draw from fixed preparations of chromosomes viewed from microscopes, hypotheses about the fine structure of chromosomes were doomed to be conjectural until the 1930's. ${ }^{21}$ As a consequence, even among the advocates of the chromosome theory of heredity, there were still many divergences about the modalities of the hypothetical "location" of genes "on" chromosomes.

\subsection{Partial linkage and chiasmatypie.}

\subsubsection{Partial linkage.}

From 1905 on, geneticists observed a phenomenon, which seems to contradict Mendel's second law. New data ${ }^{22}$ showed that some genes tend to be inherited together, without being always so. For instance, genes of Lathyrus odoratus responsible for the colour of the petals, on the one hand, and for the shape of the seeds, on the other, appear to be "partially linked" (or "coupled"). They are not randomly redistributed, contrary to what

19 In particular, nothing, enabled cytologists to settle the question of the individuality (both morphological and functional) of the chromosomes (see Dunn, 1965; Lederman, 1989).

20 About Morgan's intellectual evolution, see (Carlson, 1967; Allen 1978). More precisely on his conversion to the chromosome theory, see (Lederman, 1989).

21 Painter (1934) developed a technique to observe the fine structure of the giant salivary gland chromosomes of Drosophila.

22 The first case of partial linkage (or rather "coupling of traits") was reported by Bateson et al. (1905). 
Mendel's second law would predict: partially linked genes are inherited together in more than $50 \%$ of the cases. But their association is not systematic either (they are inherited together in less than $100 \%$ of the cases). Systematic association (or complete linkage) could be explained by the hypothesis that only one gene is responsible for these two characters.

Table 1 shows the expected distribution of genes in germ cells (for a cross involving two homozygote parents for genes A and B) for respectively complete linkage, independent assortment, and partial linkage.

\begin{tabular}{|c|c|c|c|c|}
\hline & AB & Ab & aB & ab \\
\hline $\begin{array}{c}\text { Complete link- } \\
\text { age }\end{array}$ & 50 & 0 & 0 & 50 \\
\hline $\begin{array}{c}\text { Independent } \\
\text { assortment }\end{array}$ & 25 & 25 & 25 & 25 \\
\hline $\begin{array}{c}\text { Partial link- } \\
\text { age }\end{array}$ & $50-r$ & $r$ & $r$ & $50-r$ \\
\hline
\end{tabular}

Table 1. Expected distribution of genes in germ cells for respectively complete linkage, independent assortment, and partial linkage.

Let us call $R$ the proportion $2 r$ (which corresponds to the sum of the "anomalous" cases). It is said that there was a recombination of the genes in $R$ \% of the cases (so $R$ is the percentage of recombination).

A few years after the first observations of cases of partial linkage, Morgan's work on Drosophila melanogaster (Morgan, 1910b) revealed the existence of sex linkage. Sex linkage means that some genes (for example the ones responsible for eye colour and size of the wings) appear to be linked to what was assumed to be the genes responsible for sex determination. ${ }^{23}$ Moreover, the various sex-linked characters appeared to be partially linked with each other. For instance, individuals that are identical to their mother regarding their eye colour are also observed to be identical to her regarding the size of their wings in more than $50 \%$, but less than $100 \%$ of the cases. The discovery of this relation between partial linkage and sex linkage played a crucial role in Morgan's adoption of the chromosome theory of

23 In 1891 already, cytologists had identified a non-paired chromosome (a chromosome lacking its homologue), which Wilson called "X". But the hypothesis of the chromosome determination of sex was controversial until the 1910's. 
heredity. Another key element was a cytological observation made by Janssens in 1909 .

3.2.2 Janssens' observation of chromosomes' intertwining. The chiasmatypie hypothesis.

In 1909, the cytologist Janssens observed an intertwining of homologous chromosomes during meiosis (fig. 3 ). He conjectured that homologous chromosomes might exchange segments while intertwining. Note, however, that no such exchange was observed before the 1930's. Janssens called this putative physical exchange of segments of chromosomes "chiasmatypie".
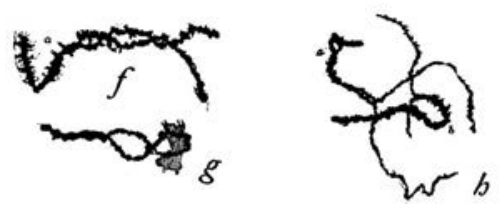

Fig. 3. Chromosomes intertwining in Batracoseps (Janssens, 1909).

\subsection{Morgan's theory of crossing-over as a mechanistic explan- ation of partial linkage.}

Janssens' observation and formulation of the chiasmatypie hypothesis, together with growing evidence for the hypothesis that sex was determined at the chromosomal level, and advances in the knowledge of sex linkage, suggested to Morgan a mechanistic explanation of the phenomenon of partial linkage, namely the theory of crossing-over.

\subsubsection{Linkage groups and crossing-over.}

Morgan hypothesised that groups of genes were linked together on what he called "linkage groups". Such linkage would explain their tendency to be inherited together (i.e. not to segregate independently from one another). He further hypothesised that the physical reality corresponding to the linkage groups were the chromosomes.

Relying on the chiasmatypie hypothesis, he suggested that linkage groups would sometimes break during the formation of germ cells, which might sometimes result in an ordered exchange between portions of homologous linkage groups. The consequence 
of this exchange is the recombination of the genes lying on these portions. Morgan and Cattell (1912) called such putative exchange "crossing-over". Crossing-over (i.e. exchange of genes between linkage groups) would thus be the genetic consequence of chiasmatypie (i.e. exchange of portions of chromosomes), and would itself provide an explanation of genes' recombination.

\subsubsection{Linearity.}

Morgan's theory of crossing-over contains one more hypothesis ${ }^{24}$, which is crucial for the rest of the story. It states that linkage groups are line-shaped. As appears in figure 4, according to Morgan's model, not only do genes lie on chromosomes, but also are they ordered in a linear fashion along them, like beads on a string. This hypothesis of linearity was prompted by a phenomenon evinced by breeding experiments on Drosophila: geneticists could observe that the frequencies of recombination were additive. What does that mean? Let us consider three genes $A, B$, and $C$, belonging to the same linkage group. Let us call $R(A C)$ the frequency of recombination for $A$ and $C$, namely the frequency of their being inherited separately (which has to be less than $50 \%$, since they are linked). Saying that frequencies of recombination are additive means that $R(A C)=R(A B)+R(B C)$. This equation suggests that genes are arranged in a linear fashion.

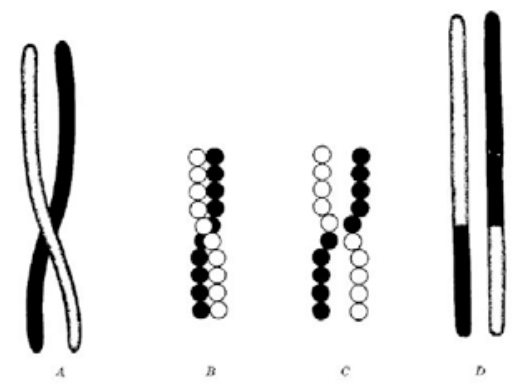

Fig. 4. The mechanistic model of crossing-over (Morgan et al., 1915, p. 60).

3.3.3 Proportionality of recombination frequency and "distance".

Drawing from the hypotheses of linearity and crossingover, Morgan suggested that the percentage of crossing-over be-

24 "Crossing-over" refers to the putative phenomenon of gene exchange. Morgan's theory of crossing-over involves the hypothesis of crossing-over, together with other hypotheses. 
tween two genes (their recombination frequency) is proportional to the "distance" between these genes on the linkage group. Indeed, as appears in the model of crossing-over schematically presented in figure 4, the more distant from each other two genes are, the more a break between them is likely to occur, and hence the more they are likely to be redistributed separately.

\subsection{First reflections on the relation of the theory of crossing- over and the chromosome theory.}

Morgan's formulation of the theory of crossing-over is historically inseparable from his adoption of the chromosome theory, and the two theories were themselves thought of as two sides of the same coin. This supposed link between the two was spectacularly confirmed by the work of Morgan's group in the following years. However, the conceptual relations of the theory of crossing-over with its cytological counterpart are not as straightforward as it might seem.

In proposing what he presents as a "comparatively" simple explanation based on results of inheritance" of various characters in Drosophila, Morgan writes:

The results are a simple mechanical result of the location of the materials in the chromosomes, [...] and the proportions that result are not so much the expression of a numerical system as of the relative location of the factors in the chromosomes. [...] Cytology furnishes the mechanism that the experimental evidence demands. (Morgan, 1911a, p. 384, italics original)

In this quote, Morgan stresses that his mechanistic explanation of partial linkage is provided by cytology: the genetic phenomena are the "result" of a chromosomal underlying reality. From that perspective, the change undergone by the science of heredity appears as some kind of reduction to the cytological level: crossing-over (gene exchange) is nothing but chiasmatypie (exchange of chromosomes' portions). Genetics has now something to say about the material implementation of the genes: after having been described as pure abstract units by early Mendelism, and before being identified to DNA segments by molecular biology, genes are now spatially localisable entities.

25 The comparison is with Bateson and Punnett's (1908, 1911) explanation in terms of "coupling" (or "attraction") and "repulsion". 
However, the theory of crossing-over can also be understood as conceptually independent from any cytological hypothesis. In Morgan's (1928) statement of the "theory of the gene", the whole theory, including the hypothesis of crossing-over, is stated without any reference to cytology:

The theory states that the characters of the individual are referable to paired elements (genes) in the germinal material that are held together in a definite number of linkage groups; it states that the members of each pair of genes separate when the germ-cells mature in accordance with Mendel's first law, and in consequence each germ-cell comes to contain one set only; it states that an orderly exchange - crossing-over - also takes place, at times, between the elements in corresponding linkage groups; and it states that the frequency of crossing-over furnishes evidence of the linear order of the elements in each linkage group and of the relative position of the elements with respect to each other. (Morgan, 1928, chap. 1, p. 25)

To be sure, Morgan did believe - and the rest of the story proved he was right to - that chromosomes were the physical bases of the linkage groups. The rest of his 1928 book is precisely intended to advocate the chromosome theory of heredity, as the best candidate explanation of crossing-over. However, the mechanistic explanation of partial linkage provided by the theory of crossing-over is conceptually independent from any hypothesis about the cytological bases of heredity, and Morgan was clearly aware thereof. ${ }^{26}$ As such, it does not include any statement concerning the physical processes, by which linkage is maintained and can be broken.

In sum, the change undergone by genetics in the 1910's consists of the introduction of a mechanistic explanation of the genetic phenomena (theory of crossing-over), together with a hypothesis about the material implementation of this mechanism (chromosome theory). But there is no description of how this particular implementation causes the mechanism. Indeed, the chromosome theory, as such, does not say anything about the physicochemical nature of linkage groups. ${ }^{27}$ Although it comes

\footnotetext{
26 According to the context, Morgan would either insist on this independence, or, on the contrary, emphasise how extraordinary a consequence it would be if the two levels of phenomena were not, in fact, related. Compare, for instance, the quote above with the following one: "The cytologist [...] has given an us an account of the chromosomes that fulfils to a degree the requirements of genetics. When we recall the fact that much of the evidence was obtained prior to the rediscovery of Mendel's paper, and that none of the work has been done with a genetic bias, but quite independently of what the students of heredity were doing, it does not seem probable that these relations are mere coincidences, but rather that students of the cell have discovered many of the essential parts of the mechanism by which the hereditary elements are sorted out according to Mendel's two laws and are interchanged in an orderly way between members of the same pair of chromosomes." (Morgan, 1928, chap. 3, p. 44)

27 Even in the 1930 's, when classical genetics is already a mature science, the mechanism in virtue of which a chromosomal break causes a genetic exchange is
} 
with a cytological hypothesis, the explanation provided by the mechanistic model itself is not cytological. This means that the mechanistic model schematised in figure 4 would still be explanatory if the structure represented in the schema was not a chromosome. Let me now turn to the study of linkage mapping, as a way to get a deeper understanding of these issues.

\section{THE REPRESENTATIONAL TECHNIQUE OF LINKAGE MAPPING}

At the core of the research program of the Drosophila group was the development and application of the technique of linkage mapping, whose design was grounded in Morgan's theory of crossing-over. Constructed on the basis of statistical data obtained through breeding experiments, linkage maps were primarily intended to represent the relative location of the genes along the chromosomes. Through striking predictions in both the cytological and the genetic domains, the mapping enterprise enabled Morgan's group to adduce more and more evidence in favour of the chromosome hypothesis. In this section, I will first present the mapping scheme, and then propose an analysis of the form and content of the maps.

\subsection{Sturtevant's (1913) mapping scheme}

In 1913, Alfred Sturtevant transforms Morgan's theory of crossing-over into a mapping scheme for the linkage groups. Assuming, with Morgan, that the recombination frequency between two genes of a given group is a function of the distance between them, Sturtevant proposed that this frequency could be used as an index of the distance separating these two genes on the chromosome. This opens up the possibility of mapping the relative ordering of the genes on a one-dimensional graph.

unknown. In fact, as Morgan clearly acknowledges in his Nobel Prize lecture, classical geneticists can remain agnostic about whether genes are "hypothetical unit[s]" or "material particle[s]". "In either case, he adds, the unit is associated with a specific chromosome, and can be localised there by purely genetic analysis. Hence, if the gene is a material unit, it is a piece of a chromosome; if it is a fictitious unit, it must be referred to a definite location in a chromosome - the same place as on the other hypothesis. Therefore, it makes no difference in the actual work in genetics which point of view is taken." (Morgan, 1935, p. 315) 
4.1.1 The scheme. Exceptions to additivity and double crossingover.

On the basis of the recombination frequencies calculated from the results of breeding experiments (shown as "proportion of cross-overs" ${ }^{28}$ in table 2), Sturtevant (1913) constructed the map for one linkage group of Drosophila (the group of the socalled "sex-linked" characters, corresponding to the $\mathrm{x}$ chromosome). The map is presented in figure 5.

\begin{tabular}{|c|c|c|}
\hline YACTORB CONCERAED & $\begin{array}{l}\text { PROPORTION OF } \\
\text { CROBS-OVERB }\end{array}$ & PER CENT OF CROBS-OVERB \\
\hline $\mathrm{BCO} \ldots \ldots$ & $\frac{193}{16287}$ & 1.2 \\
\hline BO $\ldots \ldots \ldots$ & $\frac{2}{373}$ & 0.5 \\
\hline BP $\ldots \ldots \ldots \ldots \ldots \ldots \ldots$ & $\frac{1464}{4551}$ & 32.2 \\
\hline BR....... & $\frac{115}{324}$ & 35.5 \\
\hline BM......... & $\begin{array}{l}260 \\
693\end{array}$ & 37.6 \\
\hline COP..... & $\frac{224}{748}$ & 30.0 \\
\hline COR........ & $\frac{1643}{4749}$ & 34.6 \\
\hline COM.... & $\begin{array}{c}76 \\
161\end{array}$ & 47.2 \\
\hline OP.... & $\begin{array}{l}247 \\
836\end{array}$ & 29.4 \\
\hline OR................ & $\begin{array}{l}183 \\
538\end{array}$ & 34.0 \\
\hline OM....... & $\begin{array}{l}218 \\
404\end{array}$ & 54.0 \\
\hline CR...... & $\begin{array}{r}236 \\
829\end{array}$ & 28.5 \\
\hline CM..... & $\begin{array}{l}112 \\
333\end{array}$ & 33.6 \\
\hline $\mathrm{B}(\mathrm{C}, \mathrm{O}) \ldots$ & $\frac{214}{21736}$ & 1.0 \\
\hline$(\mathrm{C}, 0) \mathrm{P} \ldots$ & $\frac{471}{1584}$ & 29.7 \\
\hline$(\mathrm{C}, \mathrm{O}) \mathrm{R} \ldots$ & $\frac{2062}{6116}$ & 33.7 \\
\hline$(\mathrm{C}, \mathrm{O}) \mathrm{M} .$. & $\begin{array}{l}406 \\
898\end{array}$ & 45.2 \\
\hline PR..... & $\begin{array}{c}17 \\
573\end{array}$ & 3.0 \\
\hline PM..... & $\frac{109}{405}$ & 26.9 \\
\hline
\end{tabular}

Table 2. Table of recombination frequencies (Sturtevant, 1913, p. 48).

28 "Cross-over" is synonymous with "crossing-over". 


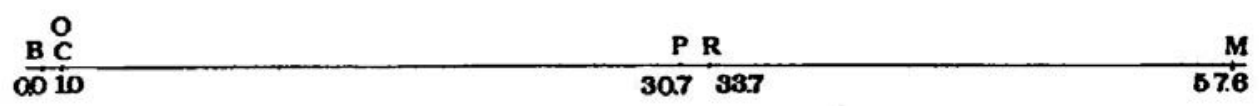

Fig. 5. Linkage map corresponding to table 2 (Sturtevant, 1913, p. 49).

However, for long distances (corresponding to high recombination frequencies), some experiments (Morgan, 1911b; Morgan and Cattell, 1912) showed exceptions to additivity. This means that, for two genes $A$ and $C$ with high recombination frequency $R(A C)$, one finds $R(A C)<R(A B)+R(B C)$, instead of $R(A C)=R(A B)+R(B C)$. But, rather than rejecting the hypothesis of linearity (which was suggested by the observation of additivity, as explained above, subsection 3.3.2), Sturtevant hypothesised that there could be more than one crossing-over occurring on the same linkage group at the same time. That would explain the exceptions to additivity for long distances. As appears in figure 6, which is a schematic representation of the three steps of a double crossing-over, the genes located at the extremities of the linkage groups, and separated by two breaks (here, genes $W$ and $B r$ ), are, in the end, inherited together (they remain on the same chromosome - there is no recombination). On the other hand, they do not remain on the same chromosome as $M$, which is located between the two breaks. Hence, for $W$ and $B r$, double crossing-over (double "breaks") contributes to cancel the recombination.

[...] if a break occurs between $B$ and $P$, and another between $P$ and $M$, then, unless we can follow $P$ also, there will be no evidence of crossing over between $B$ and $M$, and the fly hatched from the resulting gamete will be placed in the non-cross-over class, though in reality he represents two cross-overs. (Sturtevant, 1913, p. 50-51, italics mine)

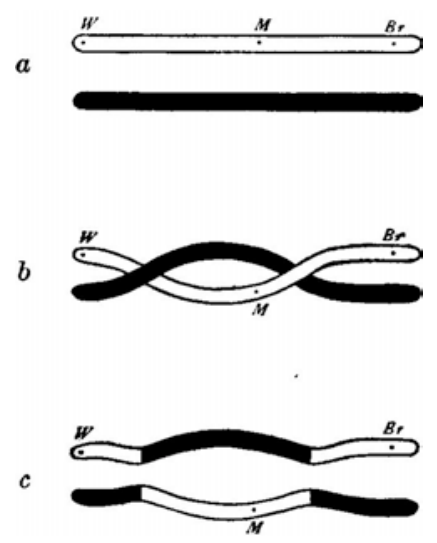

Fig. 6. Schematic representation of double crossing-over (Morgan et al., 1915, p. 62 ). 
Once the possibility of double crossing-over is acknowledged, the mapping scheme has to be modified. Following the idea underlying the hypothesis of proportionality of crossingover with distance (subsection 3.3.3), Sturtevant assumes that the more distant from each other two genes are, the more multiple breaks between them are likely to occur. Hence, high recombination frequencies (corresponding to long distances) cannot be reliably used as indices of distances. However, for shorter distances, multiple crossing-over are less likely to occur (and, in fact, there are much fewer exceptions to additivity).

Sturtevant thus chooses to construct his map by relying on short distances. Long distances on the map therefore correspond to the sum of short distances, rather than to the observed recombination frequencies between the most distanced genes. This appears clearly when one considers the table of the recombination frequencies (table 2) and its corresponding map (fig. 5). The table displays the proportions of crossing-over for each pair of genes (their recombination frequency), and the corresponding percentage, which is supposed to give the distance between them. Consider BM: the table says that, out of 693 cases, $B$ and $M$ were inherited separately 260 times, that is, 37,6\% of the cases. However, on the map, the distance between $B$ and $M$ is 57,6 (and not 37,6 ). This is because this distance was calculated by adding up short distances, rather than by relying on the recombination frequencies that could be inferred from the phenotypic data.

\subsubsection{Maps construction and conceptual development.}

Although the mapping scheme could be described as a mere practical application of the theory of crossing-over, its design and elaboration resulted in a genuine conceptual novelty. Indeed, when one further analyses the definitions of crossingover, and of genetic distance, which underlie sturtevant's mapping scheme, it appears that the construction of maps contributed to the conceptual development of the theory.

\subsubsection{Phenotypical, genotypical, and physical data.}

Before turning to crossing-over and distance, let me make a few remarks about the different levels of analysis involved in 
the construction of maps. Indeed, one can speak of "data" and of "observation" in several senses, which call for some clarification.

- The raw data, from which the maps are elaborated, are the phenotypical traits of the individual hybrid flies bred in the laboratory (e.g. eye colour, size of the wings, etc.). The phenotypical traits are observed in a strict sense (although microscopes might be used to magnify some traits). Let me call this level of data the "phenotypical level".

- The numerical data displayed in table 2, under the heading "proportions of cross-overs" are the result of a first inferential process. These are statistical data, obtained through the processing of the raw data. In a looser sense of "observation", it can be said that these proportions of crossing-over are observed, since they are sort of directly inferred from the raw data about phenotypes. These "proportions of cross-overs" are about effective recombinations (i.e. separated inheritance of genes that are partially linked). "Proportion of crossingover", in this sense, is synonymous with "recombination frequency". I will refer to this level of data as the "genotypic level".

- The distances shown on the map are the result of a second, more complex ${ }^{29}$, processing. As we have seen, Sturtevant's scheme consists in constructing linkage maps on the basis of short distances (rather, of small proportions of crossing-over low recombination frequencies), because of the exceptions to additivity and the resulting hypothesis of double crossing-over. Hence, the longer distances on the map do not correspond to the proportions of crossing-over (or recombination frequencies) displayed in the table, of which I have said that they are "observed" in the sense that they are (relatively) simply inferred from the raw data. Distances on the map rather correspond to the putative number of real or physical breaks and exchanges of genes, whose genotypic effect might be cancelled - which might result in no crossing-over at the genotypic level (no recombina-

29 I am not suggesting that the statistical processing of the raw data is an easy process. But, as we will see, the process that leads to the conversion of the recombination data into distances involves additional hypotheses. 
tion), hence no observable effect at the phenotypic level. I propose to call this level the "physical level". ${ }^{30}$

\subsubsection{The notions of crossing-over and distance.}

Morgan and Cattell (1912) first proposed the term "crossing-over" to refer to the putative gene exchange resulting in the separated inheritance of partially linked genes (see 3.3.1). Before the mapping enterprise, and before the hypothesis of double crossing-over, there was no reason to distinguish between gene recombination (separated inheritance, "observed" at the genotypic level), and gene exchange at the physical level (which was inferred as an explanation of the former). The two were certainly distinguishable, crossing-over being the hypothetical explanation of recombination, but, when it came to counting them and establishing proportions, "crossing-over" was used to refer to both: as already highlighted above, "proportions of crossovers" are equivalent to "recombination frequencies".

However, once the possibility of multiple crossing-over (in the sense of physical break and exchange of portions of linkage groups at the physical level) is acknowledged, "crossing-over" becomes highly ambiguous. Sturtevant (and more generally Morgan's group) actually uses the term "crossing-over" (or "cross-over") in two different senses. As shown in table 2, it is often used to refer to (effective) gene recombination at the genotypic level. But, in the very expression "double crossover", the term "cross-over" clearly refers to physical gene exchange. However, two crossing-over at the physical level might result in no crossing-over in the sense of recombination. Hence, proportions of crossing-over in the sense of real, physical exchange, are not equivalent to recombination frequencies (the "proportions of cross-overs" displayed in Sturtevant's table). Sturtevant was well aware of this ambiguity, as appears in the quote above ("the fly [...] will be placed in the non-cross-over class, though in reality he represents two cross-overs "). How-

30 I could call this the "cytological" or "chromosomal" level. However, as I have noted earlier (subsection 3.4), the mechanistic model of crossing-over could work even if linkage groups were not based on chromosomes. Physical crossing-over (physical ordered exchanges between portions of linearly arranged linkage groups) could be distinct from chiasmatypie (exchanges of portions of chromosomes). These putative physical crossing-over, as I have emphasised, are not observed with microscopes, unlike the intertwining of chromosomes (from which Janssens had inferred non observed - but in principle observable - breaks and exchanges). 
ever, surprisingly enough, no real clarification of the vocabulary was implemented. ${ }^{31}$ Hence, the design of the mapping scheme resulted in a change in the meaning of crossing-over, which was not explicitly stated by Morgan's group.

Let me now consider the notion of genetic distance. This concept really emerged from the design and development of the mapping technique. In Morgan's theory of crossing-over, which suggested that recombination frequencies might be proportional to distances, the notion of distance had a purely physical sense: it referred to the distance separating two genes on their linkage group. However, "mapping" or "genetic distance" (i.e. distance as measurable on the map) is not strictly equivalent to physical distance. By reading Sturtevant's paper carefully, one can notice a shift in the meaning of distance in the very course of the paper. At the beginning, "distance" clearly refers to the physical distance separating two genes:

It would seem, if this hypothesis be correct, that the proportion of "crossovers" could be used as an index of the distance between any two factors. Then by determining the distances (in the above sense) between $A$ and $B$ and between $\mathrm{B}$ and $\mathrm{C}$, one should be able to predict $\mathrm{AC}$. For, if proportion of cross-overs really represents distance, $A C$ must be approximately, either $A B$ plus $B C$, or $A B$ minus BC, and not any intermediate value. (Sturtevant, 1913, p. 45, italics mine )

The phrase I have emphasised in the quote clearly implies that proportion of crossing-over is not distance (but can be used as an index of it). However, at the end of the paper, genetic distance (whose values are displayed on the map) is proportion of (real) crossing-over. Hence, mapping (or cartographic) distance is calculated on the basis of statistical data, and is not conceptually equivalent to physical distance.

True, since it is defined as the proportions of real, physical crossing-over, mapping distance still has a physical meaning. But its metric, so to speak, is different. In fact, as Sturtevant was well aware of, already in the 1913, there is no reason to assume that the chromosomes are equally likely to break on every point. ${ }^{32}$

Of course there is no knowing whether or not these distances as drawn represent the actual relative spatial distances apart of the factors. Thus the dis-

31 This issue is not merely terminological: in the debate opposing William Castle and Morgan's group in 1919, the different actors' uses of the term reveal their diverging theoretical commitments (see Vorms, 2013a).

32 Advances in cytology later confirmed this: chromosomes are much less likely to break near the centromere. Hence, genetic distance is a measure of length combined with strength. 
tance $C P$ may in reality be shorter than the distance $B C$, but what we do know is that a break is far more likely to come between $C$ and $P$ than between $B$ and $C$. Hence, either $C P$ is a long space, or else it is for some reason a weak one. The point I wish to make here is that we have no means of knowing that the chromosomes are of uniform strength, and if there are strong or weak places, then that will prevent our diagram from representing actual relative distances - but, I think, will not detract from its value as a diagram. (Sturtevant, 1913 , p. 49)

Genetic distance and physical distance, whether or not they have the same value, are not the same concepts: they do not have the same definition. Genetic distance is a very complex concept, neither purely statistical, nor purely physical. All this should be clarified in the analysis of the form and content of the maps I will now propose.

\subsection{To what type of representation do maps belong?}

Let me know further analyse the content and form of linkage maps, namely what they represent, and how. Recalling my characterisation of the forms of representation typical of Mendelism and cytology respectively, I will tackle these issues by asking the following question: Are linkage maps Mendelian or cytological representations? Should they be interpreted as diagrammatic, or as schematic representations?

4.2.1 Schematic representations of chromosomes, obtained through Mendelian techniques?

Maps are constructed by relying on Mendelian techniques (breeding experiments and statistical analysis). In that sense, they are not the result of any abstraction process from a cytological representation, unlike the schematic drawing of a cell or of a chromosome. However, it often happens that the construction rules of two representations (and the techniques by which their source data are gathered) are different, while their interpretation rules are the same. For instance, a realistic handdrawing is not created by the same process as a digital picture that has been processed so as to look like a hand-drawing. But, for one to draw information about the scene represented, the two images are to be interpreted following the same rules. In the present case, the resulting map is intended to represent (aspects of) the structure of chromosomes. Sturtevant (1913) explicitly presents his map as a representation of the relative location of the genes on the chromosome $x$ of Drosophila. More- 
over, the very enterprise of mapping yielded confirmation of the chromosome theory, and knowledge of the structure and role of the four chromosomes of Drosophila. Finally, in the 1930's, it became possible to map linkage maps onto cytological maps (obtained through microscope techniques, see Painter 1934, and figfigure 7 ).

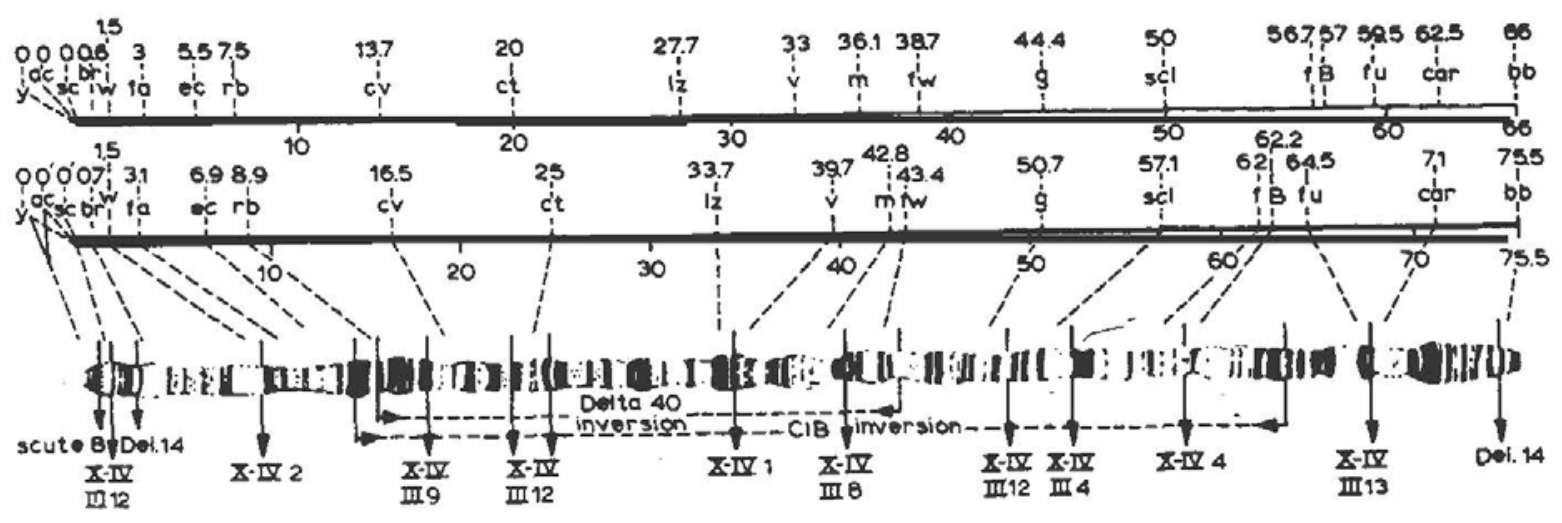

Fig. 7. Genetic map (above) and cytological map of the salivary gland of the female larva of Drosophila melanogaster. Correspondences between the loci of the genetic map with homologous loci of the salivary chromosomes are indicated by oblique lines (Painter, 1934, pp. 452-453).

Hence, even if genetic distance might not correspond exactly to physical distance - if the metric is not preserved -, at least the topological relations are preserved (the relative ordering of the genes). In that sense, maps are cytological-like (schematic) representations. They are established through Mendelian techniques, but the resulting representation has to be read as a schematic drawing representing the relative ordering of the genes on the chromosomes. In fact, they are tools of inquiry into the structure of chromosomes.

4.2.2 Mendelian diagrams displaying statistical data about recombination frequencies?

Nevertheless, it is worth acknowledging that the technique of mapping would still have been meaningful and useful, had the chromosome theory turned out to be false. In fact, maps display in a graphical way the statistical data contained in the corresponding tables. Even if they did not represent chromosomes, and not even any real physical structure, maps could still serve as tools to visualise statistical data and make predictions more easily than with the corresponding tables. As Morgan states it 
in his Nobel lecture in 1935, "this ability to predict would in itself justify the construction of [...] maps, even if there were no other facts concerning the location of the genes." (Morgan, 1935, p. 315) Maps would contain no more information than the tables, but they might be much more efficient as predictive tools.

From such a perspective, maps are mere diagrammatic ${ }^{33}$ extensions of the Mendelian symbolism, just like Punnett squares. They are only metaphorically spatial (like a temperature graph, prompting one to say that temperature is "high" or "low"), mapping distances standing for mere probabilities. They are pure diagrammatic presentations of statistical data, with no spatial meaning per se. The historical fact that they could actually be mapped onto chromosome maps in the 1930's cannot be invoked to settle, a posteriori, the conceptual issue of their meaning. Without the need to invoke such historical argument, I will now show that this interpretation is not tenable.

4.2.3 Maps as theoretical representations embodying a mechanistic hypothesis.

Although nothing proves that mapping distances correspond to real distances on the chromosomes, they do not merely correspond to simple statistical data. Indeed, as I have explained in section 4.1.2, distances on the map do not (always) correspond to the observed recombination frequencies (at the genotypic level), but rather to the proportion of real exchanges at the physical level. Long distances stand for the (putative) probability of physical crossing-over.

True, the physical basis of linkage groups could be something else than chromosomes without maps' loosing their meaning and usefulness. But, whatever their physical basis, linkage groups have to be thought of in spatial terms, if one wants to understand the mapping scheme. Hence, maps have to be read as schematic representations, rather than as extensions of the Mendelian symbolism: they involve mechanistic, hence spatial, reasoning. In fact, the schematic model shown in fig. 4 underlies their scheme. Although they are constructed on the basis of statistical data obtained through breeding experiments, the con-

${ }^{33}$ Graphs belong to the broad category of diagrammatic representation: spatial relations within them stand for non-spatial relations. 
version of these data into genetic distances implies a mechanistic, spatial model - if not the chromosome theory. If one does not think of the map as having a spatial meaning, the concept of distance becomes terribly complex and ill-defined; in fact, if one rejects the mechanistic model, the definition of distance changes, depending on whether one consider long, or short distances (see subsection 4.1.2.2).

More practically, even if one wants to use the map only as a predictive tool for gene recombination, one has to read it as a schematic representation: in order to retrieve information about recombination frequencies, one has to interpret distance in a spatial way (spatial relations within the map have to be interpreted as standing for spatial relations). Otherwise, it is practically impossible to read the very genetic data off the map. If one refuses to consider maps as theoretical representations - in the sense that they bear a theoretical (mechanistic) explanation of the genetic phenomena, maps are far from handy predictive tools, and the mapping scheme is unjustifiably complex (see Vorms, 2013a). Maps do not only suggest a mechanistic explanation; they rather embody this explanation - their rules of construction and of interpretation involve it. They are genuine theoretical representations, from which new concepts emerge.

4.2.4 Conceptual change as representational change. The spatialisation of the gene.

The birth of classical genetics is the result of the junction of two disciplines. It can be described as resulting from the integration of a cytological hypothesis into the science of heredity, together with a mechanistic explanation. I do not contest the correctness of this description. But I hope to have shown that one gets a finer-grained and deeper understanding of the integration of the modes of analysis of cytology and Mendelism by studying the concrete representations that were constructed, and reasoned with, by the geneticists, than by exclusively focusing on (linguistically represented) hypotheses. The conceptual change undergone by genetics in the 1910's is best described as a representational change: spatial thinking becomes essential to genetics.

As I have emphasised in section 3, the introduction of cytological hypotheses into genetics does not contribute anything 
to the knowledge of the material nature of the gene (i.e. its physicochemical constitution). Merely describing the birth of classical genetics as the result of the adoption of the chromosome theory of heredity, hence as a step towards the materialisation of the gene, would thus overstate the explanatory import of cytology. It would also obscure the role cytology actually played in shaping the geneticists' representation and understanding of the mechanism of crossing-over. Morgan's model was clearly prompted by his conception of the kind of explanation cytology should provide to genetics, namely a mechanistic, rather than a chemical one. ${ }^{34}$

Similarly, focusing on the theory of crossing-over, as a set of hypotheses providing a mechanistic explanation of partial linkage would not do justice to the conceptual novelty arising from the mapping technique itself. New concepts emerged from this representational technique. In particular, it is difficult - if not impossible ${ }^{35}$ - to grasp the complexity and subtlety of the concept of mapping distance by merely considering the hypotheses at play, rather than the mapping scheme itself. The design of linkage mapping introduces a novel way of representing, and reasoning about the genetic phenomena. Representations such as linkage maps are not the expressions of an underlying theory, but rather the very locus of theorising.

As a result, paying attention to the representational forms used in scientific practice is a way for the philosopher, and for the historian, to capture aspects of the conceptual content, and of the conceptual development, of a science, which are obscured by more classical approaches. As I have just shown, in the case of genetics, this approach unravels the complex role of the chromosome theory within the conceptual components of classical genetics. It also provides us with a fine-grained view of

\footnotetext{
34 By contrast, Castle's (1919) rival map model was (partially) prompted by his conception of chromosomes as complex chemical molecules, to which genes are supposed to be attached by molecular, rather than mechanical, forces. To him, recombination is rather the result of a chemical reaction, than of a mechanical process (see Wimsatt, 1987; Vorms, 2013a). More generally, I suggest that the way different geneticists understood the conceptual articulation of cytological hypotheses with Mendelian ones, and their own representation of the structure of chromosomes, drove the way they constructed, and interpreted, maps (see Vorms, 2013b).

35 My point is not that the content of maps (both the data they convey and the hypotheses they embody) cannot be put into words - this paper proves the contrary - but that it is very hard to grasp this content without analysing the form of maps, and that the conceptual novelty arouse from the very design of maps.
} 
the conceptual change undergone by genetics in the 1910's: it enables us both to highlight the conceptual independence of Morgan's model of crossing-over with regards to the chromosome theory, and to understand that there is a genuine theoretical novelty in the way geneticists would represent genes.

Moreover, for the scientists themselves, discussions and reflections on their representational techniques, and on the best way to construct, and interpret, the representations they use, often prompt them to make explicit, clarify, and develop, their own understanding of the theoretical constructs they are dealing with. Linkage mapping offers a striking example of this: the design of the mapping scheme, as well as the debates it gave rise to (see Vorms, 2013a, 2013b), led Morgan and his colleagues to articulate and make explicit aspects of the meaning of some concepts (crossing-over, distance) that were left implicit in the linguistic presentations of their theory. Conceptual development not only gave birth to a new representational technique, but also genuinely arose from the design and improvement of this technique.

\section{CONCLUSION}

I have proposed a study of the birth of classical genetics in the 1910's from the perspective of the forms of representation associated with the two disciplines it arose from. Scientific change is often equated with addition, subtraction, or modification of hypotheses. Prima facie, the change undergone by the science of heredity in the 1910's could be described as the addition of a cytological hypothesis, together with the mechanistic explanation it provides. Although this is not wrong, I have shown that the change undergone by genetics in the 1910's is best described as a representational change. This representational change results from the integration of the typical forms of representation of Mendelism and cytology respectively, into a new representational form, namely linkage maps. Rather than being the result, or the expression, of an underlying conceptual change, the design of the representational technique of linkage mapping both prompted and embodies the conceptual development of genetics. 


\section{REFERENCES}

Allen, G. (1978). Thomas Hunt Morgan. Princeton: Princeton University Press.

Bateson, W., Punnett, R., \& Saunders, E. (1905). Further experiments on inheritance in sweet peas and stocks: Preliminary account. Proceedings of the Royal Society, B, 77.

Bateson, W., \& Punnett, R. (1908). The heredity of sex. Science, 27 .

Bateson, W., \& Punnett, R. (1911). On gametic series involving reduplication of certain terms. Journal of Genetics, 1,293302 .

Boveri, T. (1904). Ergebnisse über die Konstitution der chromatischen Substanz des Zellkerns. Jena: G. Fischer.

Burian, R. (1985). Conceptual change, cross-theoretical explanation and the unity of science. Synthese, 33,1-28.

Carlson, E. (1967). The Gene: A Critical History. Philadelphia: W.B. Saunders, reprinted by the University of Iowa Press.

Castle, W. (1919). Is the arrangement of the genes in the chromosome linear? Proceedings of the National Academy of Sciences of the United States of America, 5(2), 25-32.

Darden, L., \& Maull, N. (1977). Interfield theories. Philosophy of science, 44(1), 43-64.

Darden, L. (1991). Theory Change in Science: Strategies from Mendelian Genetics, Oxford University Press.

Dunn, L. (1965). A Short History of Genetics. New York: McGrawHill.

Goodman, N. (1976). Languages of Art. An Approach to the Theory of Symbols $\left(2^{\text {nd }}\right.$ ed.). Indiana: Hackett Publishing Company.

Griesemer, J., \& Wimsatt, W. (1989). Picturing Weismannism: A case study of conceptual evolution. In M. Ruse (Ed.), What the Philosophy of Biology is. Essays for David Hull (pp. 75137). Dordrecht: Kluwer Academic Publishers.

Hull, D. (1972). Reduction in genetics - biology or philosophy? Philosophy of Science, 39(4), 491-499.

Janssens, F. (1909). Spermatogénèse dans les batraciens. V. La théorie de la chiasmatypie. La Cellule, 25, 387-411.

Kitcher, P. (1984). 1953 and all that. A tale of two sciences. The Philosophical Review, 93(3), 335-373.

Kohler R.E. (1994). Lords of the Fly: Drosophila Genetics and the Experimental Life. Chicago: University of Chicago Press.

Kuhn, T. (1969). Second Thoughts on Paradigms. In F. Suppe (Ed.), The Structure of Scientific Theories (pp. 459-482). Urbana: University of Illinois Press ( $2^{\text {nd }}$ ed.). 
Kuhn, T. (1970a). The Structure of Scientific Revolutions $\left(2^{\text {nd }}\right.$ ed.). Chicago: University of Chicago Press.

Kuhn, T. (1970b). Postscript. In Kuhn (1970a).

Lederman, M. (1989). Genes on Chromosomes: The Conversion of Thomas Hunt Morgan. Journal of the History of Biology, $22(1), 163-176$.

Lynch, M. (1988). The externalised retina: Selection and mathematisation in the visual documentation of objects in the life sciences. Human studies, 11, 201-234.

Maienschein, J. (1991). From presentation to representation in E.B. Wilson's The Cell. Biology and Philosophy, 6,227-254.

Mendel, G. (1866). Versuche über Plfanzenhybriden. Verhandlungen des naturforschenden Vereines in Brünn, Bd. IV für das Jahr 1865, Abhandlungen (pp. 3-47).

Morgan, T.H. (1910a). Chromosomes and heredity. American Naturalist, 44,449-496.

Morgan, T.H. (1910b). Sex-limited inheritance in Drosophila. Science, 32:, 1 .

Morgan, T.H. (1911a). Random segregation versus coupling in Mendelian inheritance. Science, 34(873), 384.

Morgan, T.H. (1911b). An attempt to analyze the constitution of the chromosomes on the basis of sex-limited inheritance in Drosophila. Journal of Experimental Zoology, 11(4), 365-413.

Morgan, T.H. (1928). The theory of the gene. New Haven: Yale University Press $\left(2^{\text {nd }}\right.$ ed.)

Morgan, T.H. (1935). The relation of genetics to physiology and medicine, Smithonian Institution. Annual Report (pp. 345359). Reprint. in J. Lindsten (Ed.), 1999. Nobel Lectures in Physiology Or Medicine: 1922-1941 (pp. 313-328). World Scientific Publishing Company.

Morgan, T.H., \& Cattell, E. (1912). Data for the study of sexlimited inheritance in drosophila, Journal of Experimental Zoology, 13, 79 .

Morgan, T.H., Sturtevant, A.H., Muller, H.J., \& Bridges, C.B. (1915). The Mechanism of Mendelian Heredity. Henry Holt and Company .

Olby, R. (1985). Origins of Mendelism. Chicago: University of Chicago Press.

Painter, T. (1934). The morphology of the $\mathrm{x}$ chromosome in salivary glands of Drosophila Melanogaster and a new type of chromosome map for this element. Genetics, 19, 448-469.

Rosenberg, A. (1985). The Structure of Biological Science. Cambridge/New York: Cambridge University Press.

Schaffner, K. (1969). The Watson-Crick model and reductionism. The British Journal for the Philosophy of Science, 20(4), 325-348. 
Simon, H., \& Larkin, J. (1987). Why a Diagram is (Sometimes) Worth Ten Thousand Words. Cognitive Science, 11, 65-99.

Sturtevant, A. (1913). The linear arrangement of six sex-linked factors in Drosophila, as shown by their mode of association. Journal of Experimental Zoology, 14, 43-59.

Sutton, W. (1903). The Chromosomes in Heredity. Biological Bulletin, 4, 231-251.

Vorms, M. (2009). Théories, modes d'emploi. Une perspective cognitive sur l'activité théorique dans les sciences empiriques. $\mathrm{PhD}$ thesis, University Paris 1. www.risc.cnrs.fr/Theses pdf/2009 Vorms.pdf

Vorms, M. (2011). Representing with Imaginary Models: Formats Matter. Studies in History and Philosophy of Science, 42(2), 287-295.

Vorms, M. (2012). Formats of Representation in Scientific Theorizing. In P. Humphreys \& C. Imbert (Eds.), Models, Simulations, and Representations (pp. 250-273). Routledge, New York.

Vorms, M. (2013a). Models of data and theoretical hypotheses: A case-study in Mendelian genetics. Synthese, 190, 293-319.

Vorms, M. (2013b). Theorizing and representational practices in classical genetics. Biological Theory, 7(4), 311-324.

Waters, K. (1990). Why the anti-reductionist consensus won't survive: The case of classical Mendelian genetics. PSA: Proceedings of the Biological Meeting of the Philosophy of Science Association, 1, 125-139.

Waters, K. (1994). Genes Made Molecular. Philosophy of Science $61,163-185$.

Wimsatt, W. (1976). Reductionism, levels of organisation and the mind-body problem. In C. Globus, C., G. Maxwell, G., \& I. Savodnik (Eds.), Consciousness and the Brain: A Scientific and Philosophical Inquiry (pp. 199-267). New York: Plenum Press.

Wimsatt, W. (1987). False models as means to truer theories. In M. Nitecki, \& A. Hoffman (Eds.), Neutral Models in Biology (pp. 23-55) . Oxford: Oxford University Press. 